\title{
A Quarter for Prevention? Global Fund Investments in HIV Prevention Interventions in Generalized African Epidemics
}

\author{
Gemma Oberth $^{1,2, *}$, Mary Ann Torres ${ }^{2}$, Olive Mumba $^{3}$, Michael O'Connor ${ }^{2}$ \\ ${ }^{1}$ Centre for Social Science Research (CSSR), University of Cape Town, South Africa \\ ${ }^{2}$ International Council of AIDS Service Organizations (ICASO), Canada \\ ${ }^{3}$ Eastern Africa National Networks of AIDS Service Organizations (EANNASO), Tanzania
}

Copyright $\bigcirc 2017$ by authors, all rights reserved. Authors agree that this article remains permanently open access under the terms of the Creative Commons Attribution License 4.0 International License

\begin{abstract}
The Joint United Nations Programme on HIV/AIDS estimates that ending AIDS by 2030 will cost $\$ 25$ billion a year. About a quarter $(26 \%)$ of this amount is required for HIV prevention. The Global Fund to Fight AIDS, Tuberculosis and Malaria is a major financier of African HIV responses and a vital source of prevention investments. A search was performed for Global Fund funding requests and signed grants from a sample of African countries over the 2014-2016 funding cycle to see if the Global Fund is investing "a quarter for prevention". Funding requests were accessed for 23 countries and signed grants were accessed for 15 countries. Some documents were not publicly available. Among the funding requests examined, an average of $16 \%$ was dedicated to HIV prevention. Wealthier countries requested more money for HIV prevention, as did countries with greater numbers of annual new infections. Of the grant agreements examined, an average of $15 \%$ of the total funding invested was dedicated to HIV prevention. For the Global Fund to achieve its HIV prevention targets in its new strategy (2017-2022) it must increase its investments in HIV prevention in Africa from current levels towards the UNAIDS benchmark of $26 \%$.
\end{abstract}

Keywords HIV, AIDS, Prevention, Prevention Spending, Global Fund, Fast-track, Key Populations, Africa

\section{Introduction}

In July 2016, the Joint United Nations Programme on HIV/AIDS (UNAIDS) announced that global efforts to reach fewer than 500,000 new HIV infections by 2020 are off track [1]. Indeed, since 2010, the number of new adult HIV infections has remained unchanged, with an estimated 1.9 million occurring globally each year [1]. However, not all countries have experienced static progress on prevention.
In sub-Saharan Africa - where $65 \%$ of all new infections globally occur - there are stark disparities in prevention progress. For instance, the percent change in new HIV infections from 2005 to 2015 among adults has decreased by more than $49 \%$ in the Democratic Republic of Congo and Senegal, yet new infections have increased by the same proportion in Kenya and Madagascar [1].

Further disparities exist by population and location. Adolescent girls in South Africa are eight times more likely to contract HIV than their male peers [2]. Sex workers in Ethiopia have an HIV prevalence of $24.3 \%$ - more than 16 times the national adult average of 1.5\% [3][4]. In Zimbabwe, HIV incidence is $2.5 \%$ in Bulawayo, compared to below $1 \%$ in much of the rest of the country [5].

The freeze on prevention progress is occurring at the same time as the world is preparing to achieve ambitious global targets to dramatically reduce new infections and end the epidemic as a major health threat by 2030. In November 2014, UNAIDS set global Fast-Track targets, to accelerate progress against ending AIDS. The Fast-Track includes ambitious yet attainable treatment, prevention, and discrimination targets (Table 1).

Table 1. Fast-Track Targets for Ending the AIDS Epidemic [6]

\begin{tabular}{|c|c|}
\hline By 2020 & By 2030 \\
\hline $90-90-90$ treatment & $95-95-95$ treatment \\
\hline $\begin{array}{c}\text { Fewer than } 500,000 \text { new adult } \\
\text { infections }\end{array}$ & $\begin{array}{c}\text { Fewer than 200,000 new adult } \\
\text { infections }\end{array}$ \\
\hline Zero discrimination & Zero discrimination \\
\hline
\end{tabular}

The 90-90-90 targets refer to: $90 \%$ of all people living with HIV will know their HIV status, $90 \%$ of all people with diagnosed HIV infection will receive sustained antiretroviral therapy, and $90 \%$ of all people receiving antiretroviral therapy will have viral suppression. By 2030, coverage of these three targets should reach $95 \%$.

Achieving the Fast-Track targets is estimated to avert 28 
million HIV infections between 2015 by 2030. This is modelled to deliver a 15-fold return on HIV investments, including saving \$24 billion in additional HIV treatment costs based on infections averted [6].

Much of the focus on the Fast-Track agenda has centred on the first set of targets (90-90-90). While treatment scale-up is critical, it is not the whole picture. In fact, fully achieving the 90-90-90 treatment targets is expected to avert about $60 \%$ of all new HIV infections by 2020 . The remaining $40 \%$ of new HIV infections have to be averted through other prevention methods [7].

Many African countries have embraced the second set of Fast-Track targets, focusing on HIV prevention. Kenya's HIV Prevention Revolution Road Map is a detailed sub-national location-based plan for targeted prevention interventions [8]. Zimbabwe's Roadmap to Revitalize HIV Prevention has seven strategies for revitalizing prevention towards zero new infections by 2030 , including ensuring adequate resources are set aside for prevention. South Africa's National Sex Worker HIV Plan aims to reach 70,000 sex workers and ensure that at least $95 \%$ of them use condoms with their clients and partners and that gender-based violence falls by $50 \%$ [9].

The 2016 UN Political Declaration on Ending AIDS enshrines the Fast-Track targets as binding national commitments [10]. Importantly, the Declaration also encourages countries to ensure that financial resources for prevention are adequate, constituting no less than a quarter of AIDS spending globally on average, and are targeted to evidence-based prevention measures.

Based on UNAIDS modeling, the costs of achieving the Fast-Track agenda is estimated to require an average of $\$ 25$ billion each year until $2030.26 \%$ of these resource needs are for prevention (Figure 1).

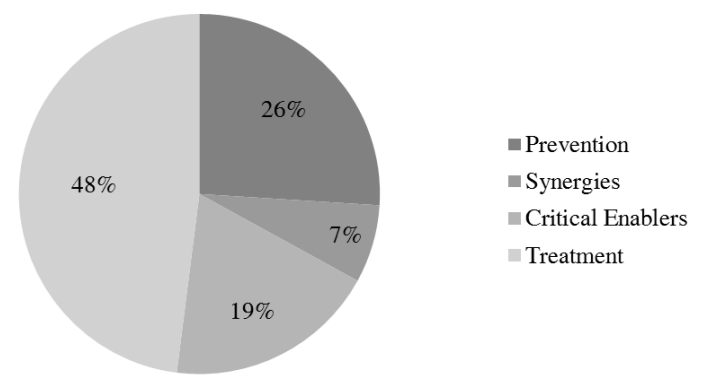

Figure 1. Global Resource Needs for the AIDS Response by 2020 [7]
The majority of new HIV infections occur in sub-Saharan Africa, yet domestic funding for HIV prevention from African governments is not commensurate. The region is largely dependent on external donors to pay for HIV information campaigns, condom distribution, voluntary medical male circumcision (VMMC) and outreach to young people and key populations [11].

Established in 2002, The Global Fund to Fight AIDS, Tuberculosis and Malaria is a major financier of African HIV responses and a vital source of prevention investments. By 2015, the Global Fund supported 3.6 million HIV-positive pregnant women to receive ARV prophylaxis in order to prevent transmission to their unborn children and distributed 5.3 billion condoms [12]. In that same year, $65 \%$ of all Global Fund resources went to sub-Saharan African countries [12].

The Global Fund's Strategy (2017-2022) is aligned to global targets, including the Fast-Track targets presented in Table 1. In addition, there are several corporate key performance indicators (KPIs) that the Global Fund has set in relation to HIV prevention (Table 2).

Table 2. Global Fund Key Performance Indicators for Prevention in 2017-2022 Strategy [13]

\begin{tabular}{|l|l|}
\hline \multicolumn{1}{|c|}{ HIV Prevention Indicator } & \multicolumn{1}{|c|}{ Global Fund Target } \\
\hline $\begin{array}{l}\text { Percentage reduction in new } \\
\text { infections/cases (average rates across the } \\
\text { three diseases) }\end{array}$ & $\begin{array}{l}38 \%(28-47 \%) \text { over the } \\
2015-2022 \text { period }\end{array}$ \\
\hline Number of males circumcised & $\begin{array}{l}22(19-26) \text { million over } \\
\text { the 2017-2022 period }\end{array}$ \\
\hline $\begin{array}{l}\text { Coverage of key populations reached } \\
\text { with evidence-informed package of } \\
\text { treatment and prevention services } \\
\text { appropriate to national epidemiological } \\
\text { contexts }\end{array}$ & $\begin{array}{l}75 \% \text { of selected countries } \\
\text { by 2019 }\end{array}$ \\
\hline $\begin{array}{l}\text { Percentage reduction in HIV incidence in } \\
\text { women aged 15-24 }\end{array}$ & $\begin{array}{l}58 \%(47-64 \%) \text { over the } \\
2015-2022 \text { period }\end{array}$ \\
\hline
\end{tabular}

While the Global Fund does not have a target on HIV prevention spending, there are two key performance indicators related to budget allocations in signed grants:

- Investment in signed HIV and HIV/TB grants dedicated to programs to reduce human rights barriers to access to reach $2.85 \%$ over the $2017-2019$ period.

- Investment in signed HIV and HIV/TB grants dedicated to programs targeting key populations to reach $39 \%$ over the 2017- 2019 period. 
Table 3. Country Epidemiological Profiles - HIV Prevention Indicators (2015) [14]

\begin{tabular}{|c|c|c|c|c|c|}
\hline Country & $\begin{array}{c}\text { Number of } \\
\text { new Infections }\end{array}$ & $\begin{array}{l}\text { Incidence } \\
\text { Rate (\%) }\end{array}$ & $\begin{array}{l}\text { Number of male } \\
\text { circumcisions } \\
\text { performed }\end{array}$ & $\begin{array}{c}\text { Condom use at last sex } \\
\text { among people (15-49) with } \\
\text { multiple sexual } \\
\text { partnerships (\%) } \\
\end{array}$ & $\begin{array}{l}\text { Knowledge about HIV } \\
\text { prevention among young } \\
\text { people }(15-24)(\%)\end{array}$ \\
\hline Angola & 26,000 & 0.19 & No data & No data & No data \\
\hline Botswana & 9700 & 0.94 & 15,722 & No data & No data \\
\hline Cape Verde & $<200$ & 0.06 & No data & No data & No data \\
\hline Ethiopia & No data & No data & No data & 0 & 28.35 \\
\hline Ghana & 13,000 & 0.08 & No data & 17.5 & 22.2 \\
\hline Guinea-Bissau & No data & No data & No data & No data & 22.3 \\
\hline Kenya & 78,000 & 0.35 & 207,014 & 0 & No data \\
\hline Lesotho & 18,000 & 1.88 & 25,966 & 46.4 & 35.5 \\
\hline Liberia & 1600 & 0.06 & No data & 20.7 & 33.5 \\
\hline Madagascar & 6300 & 0.05 & No data & 2.0 & 33.9 \\
\hline Malawi & 33,000 & 0.38 & 108,672 & 35.4 & 41.9 \\
\hline Mauritius & $<500$ & 0.04 & No data & 50.7 & 31.8 \\
\hline Mozambique & 81,000 & 0.71 & 198,340 & 26.9 & 34.9 \\
\hline Namibia & 7800 & 0.68 & 18,549 & No data & 58.3 \\
\hline Nigeria & No data & No data & No data & 64.5 & 24.4 \\
\hline Sierra Leone & 2500 & 0.07 & No data & 9.6 & 29.1 \\
\hline Somalia & 3000 & 0.05 & No data & No data & No data \\
\hline South Africa & 380,000 & 1.44 & 485,552 & No data & No data \\
\hline South Sudan & 15,000 & 0.22 & No data & No data & No data \\
\hline Swaziland & 11,000 & 2.36 & 12,952 & 71.53 & 55.96 \\
\hline Tanzania & 54,000 & 0.21 & 435,302 & No data & 43.4 \\
\hline Uganda & 83,000 & 0.51 & 556,546 & 30.1 & 38.4 \\
\hline Zambia & 60,000 & 0.85 & 222,481 & 27.1 & 43.9 \\
\hline Zanzibar & No data & No data & No data & No data & No data \\
\hline Zimbabwe & 64,000 & 0.88 & 188,732 & 44.3 & 54.7 \\
\hline
\end{tabular}

Despite African countries' acknowledgement of prevention as a priority, and the commitment of partners like the Global Fund towards supporting such initiatives, challenges persist with translating rhetoric into reality. Many countries in Africa have exceedingly high rates of new infections, driven in part by low levels of HIV knowledge, condom use, and male circumcision (Table 3). Competing demands on stretched budgets and restrictive legal and policy environments potentially limit the ability of the Global Fund to invest in HIV prevention in Africa.

In many African countries, Global Fund grants are often highly commoditized, limiting the opportunities for prevention scale-up within country allocations. For instance, in Mozambique's current grants, $87 \%$ of the $\$ 222.5$ million total is dedicated solely to the treatment, care and support budget module. These squeezes on a country's allocation leave very little room for HIV prevention to be prioritized.

Further, key populations are often criminalized, limiting (or even at times prohibiting) Global Fund prevention investments among these high-risk groups. Research has also shown that criminalization of same-sex behavior is linked to implausibly low population size estimates and inaccurate service coverage data [15]. This negatively effects fast-tracking of prevention. In Tanzania, the government has suspended certain specific Global Fund prevention programs for men who have sex with men (MSM) citing "the countries' laws, customs and traditions" in an official statement [16].

Compounding these challenges, there is not always a clear picture of whether "a quarter for prevention" is being invested. There is scant analysis and budget tracking which focuses solely on prevention funding for HIV, which limits the impact of advocacy for increased funding.

At the expert meeting to Fast-Track HIV prevention implementation in 15 Fast-Track countries, held on 23-24 March 2017 in Victoria Falls, Zimbabwe, the acting Executive Director of the Global Fund, Marijke Wijnroks, presented a call to action on HIV prevention. Indeed, one of the key objectives of the meeting was to explore opportunities for increasing investments for HIV prevention in the East and Southern African region including through 
the upcoming Global Fund applications for the 2017-2019 funding cycle.

It is within this context that we explore a central question in this study: Is the Global Fund investing "a quarter for prevention" in Africa?

\section{Methodology}

To answer this question, a search was performed for HIV and TB/HIV Global Fund funding requests and signed grant agreements from a sample of 25 African countries over the 2014-2016 funding cycle: Angola, Botswana, Cape Verde, Ethiopia, Ghana, Guinea-Bissau, Kenya, Lesotho, Liberia, Madagascar, Malawi, Mauritius, Mozambique, Namibia, Nigeria, Sierra Leone, Somalia, South Africa, South Sudan, Swaziland, Tanzania, Uganda, Zambia, Zanzibar and Zimbabwe.

Of the 25 country sample, funding requests were accessed for 23 countries. 17 funding requests were accessed from the Global Fund's website and 6 were accessed directly from country partners (as they were not publicly available online). Signed grant agreements were accessed for 15 countries. Some of the grant agreements were not publicly available from the Global Fund's website, while others were scanned to a very poor resolution and had illegible budgets.

The 23 funding requests and 15 signed grant agreements were then examined for their HIV prevention budgets. For the funding requests, the analysis includes both allocation and above allocation requests. Global Fund budget modules included in the study definition of "HIV prevention funding" included:

- Prevention programs for general population

- Prevention programs for men who have sex with men and transgender populations

- Prevention programs for sex workers and their clients

- Prevention programs for people who inject drugs and their partners

- Prevention programs for other vulnerable populations

- Prevention programs for adolescents and youth, in and out of school

HIV testing services and prevention of mother-to-child transmission were excluded from this analysis. In UNAIDS modelling, these interventions are not included in the $26 \%$ required for HIV prevention spending [17].

It is acknowledged that funding in other Global Fund budget modules may contribute directly or indirectly to HIV prevention. For instance, funding for antiretroviral therapy (ART) under the treatment, care and support module has a preventive effect, as many studies have shown that treatment scale-up for people living with HIV can help prevent new infections to their sexual partners. Further, funding under the community systems strengthening or removing legal barriers modules may support prevention.
To give depth to the results, several epidemiological and structural variables were explored along with discussion themes around specific prevention priorities and the role of civil society and communities. Epidemiological and structural variables on HIV incidence rate, number of new infections, condom use, number of male circumcisions and youth knowledge on HIV, number of people on ART and the wealth of a country were tested using the Statistical Package for the Social Sciences (SPSS) software to see if they are associated with levels of HIV prevention funding in funding requests and grant agreements. Other discussion themes were explored using qualitative methodologies.

\section{Results}

Of the 25 country sample, 23 HIV and TB/HIV funding requests were accessed, either through the Global Fund's website or directly from country partners. The 23 countries requested a total of $\$ 4,259,233,917$ in their HIV or HIV/TB funding requests. Of this amount, $\$ 668,662,399$ was requested for prevention modules, representing $16 \%$ of total funds requested. The largest proportion was for prevention among the general population, with $\$ 361,541,418$ requested for this module. This is followed by prevention programs for adolescents and youth, in and out of school, at \$132,345,794. Amounts requested for sex workers, men who have sex with men, transgender people, and people who inject drugs, were far lower.

Among the 23 countries examined, 10 countries requested "a quarter for prevention", dedicating at least $26 \%$ of their total funding requests to HIV prevention interventions (as per the UNAIDS recommended target). The remaining 13 had prevention requests below $26 \%$. See Table 4 for each country's prevention request, expressed as a proportion of their total HIV or HIV/TB funding request to the Global Fund during the 2014-2016 funding cycle.

Table 4. Proportion of 2014-2016 HIV or TB/HIV Global Fund Funding Requests Dedicated to HIV Prevention Interventions

\begin{tabular}{|c|c|}
\hline $\begin{array}{c}\text { Countries that } \underline{\text { did }} \text { request "a } \\
\text { quarter for prevention" }\end{array}$ & $\begin{array}{c}\text { Countries that } \begin{array}{c}\text { did not request "a } \\
\text { quarter for prevention" }\end{array} \\
\end{array}$ \\
\hline Angola (33\%) & Cape Verde $(15 \%)$ \\
\hline Botswana (44\%) & Ethiopia (12\%) \\
\hline Lesotho (27\%) & Ghana $(12 \%)$ \\
\hline Mauritius (67\%) & Guinea-Bissau (5\%) \\
\hline Sierra Leone $(37 \%)$ & Kenya $(10 \%)$ \\
\hline Somalia $(26 \%)$ & Liberia $(4 \%)$ \\
\hline South Africa (42\%) & Malawi (12\%) \\
\hline Uganda (31\%) & Mozambique (3\%) \\
\hline Zanzibar (31\%) & Nigeria $(7 \%)$ \\
\hline Zimbabwe $(30 \%)$ & South Sudan $(23 \%)$ \\
\hline & Swaziland (3\%) \\
\hline & Tanzania (5\%) \\
\hline & Zambia (17\%) \\
\hline
\end{tabular}




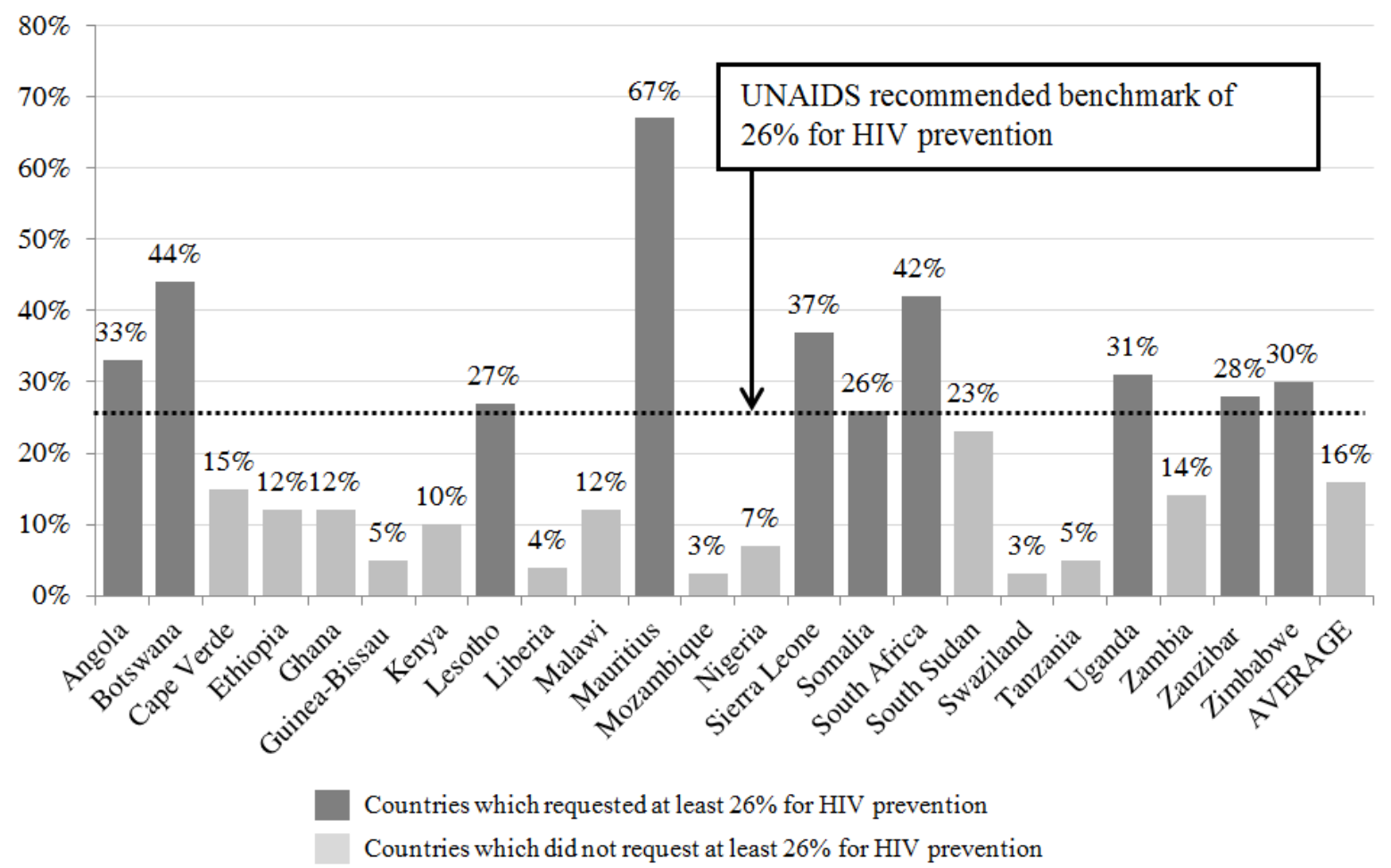

Figure 2. Proportion of HIV and TB/HIV Global Fund Funding Requests Dedicated to HIV Prevention Interventions (2014-2016 Funding Cycle)

While a relatively even number of countries $d i d$ request a quarter for prevention (10) versus did not request it (13), Figure 3 makes it is clear that there are extreme variations among countries in terms of how much as requested.

The largest absolute prevention request came from Uganda, which requested $\$ 154,936,410$ for prevention. This was largely driven by an above allocation request for prevention among the general population $(\$ 127,795,597)$.

The largest proportional request for prevention came from Mauritius, which directed $67 \%$ of its total funding request to prevention programs. The next highest proportional requests for HIV prevention came from Botswana (44\%) and South Africa (42\%). As upper-middle income countries, the Global Fund requires Mauritius, Botswana and South Africa to demonstrate that their funding requests focus $100 \%$ of the budget on underserved and most-at-risk populations and/or highest-impact interventions. Lower-middle income countries must show that at least $50 \%$ of the budget goes to these areas.

The smallest absolute prevention request came from Cape Verde, which requested $\$ 355,922$ for prevention. As the smallest country in the sample in terms of population size, and the country with the smallest Global Fund allocation amount, this is not surprising. The smallest proportional requests for HIV prevention programs came from Mozambique (3.1\%) and Swaziland (3.5\%). PEPFAR is a large investor in HIV prevention in Mozambique and Swaziland, which may have an impact on the prevention gaps that remain to be funded by Global Fund.

Of the 25 countries included in this study, 15 had publicly available signed grant agreements. In just two of these countries - Botswana and Liberia - at least a quarter of the HIV or HIV/TB signed Global Fund grant(s) for the 2014-2016 cycle is dedicated to HIV prevention interventions (Table 5; Figure 3).

Table 5. Proportion of 2014-2016 HIV or TB/HIV Global Fund Signed Grant Agreements Dedicated to HIV Prevention Interventions

\begin{tabular}{|c|c|}
\hline $\begin{array}{l}\text { Countries where the Global } \\
\text { Fund is investing "a quarter for } \\
\text { prevention" }\end{array}$ & $\begin{array}{l}\text { Countries where the Global } \\
\text { Fund } \underline{\underline{\text { is not }} \text { investing "a quarter }} \\
\text { for prevention" }\end{array}$ \\
\hline $\begin{array}{c}\text { Botswana }(33 \%) \\
\text { Liberia }(38 \%)\end{array}$ & $\begin{array}{c}\text { Angola (17\%) } \\
\text { Ethiopia (17\%) } \\
\text { Ghana (13\%) } \\
\text { Guinea-Bissau (5\%) } \\
\text { Kenya }(12 \%) \\
\text { Mozambique }(4 \%) \\
\text { Sierra Leone (20\%) } \\
\text { Somalia }(14 \%) \\
\text { South Sudan (12\%) } \\
\text { Swaziland }(16 \%) \\
\text { Tanzania }(24 \%) \\
\text { Uganda }(17 \%) \\
\text { Zambia }(11 \%)\end{array}$ \\
\hline
\end{tabular}




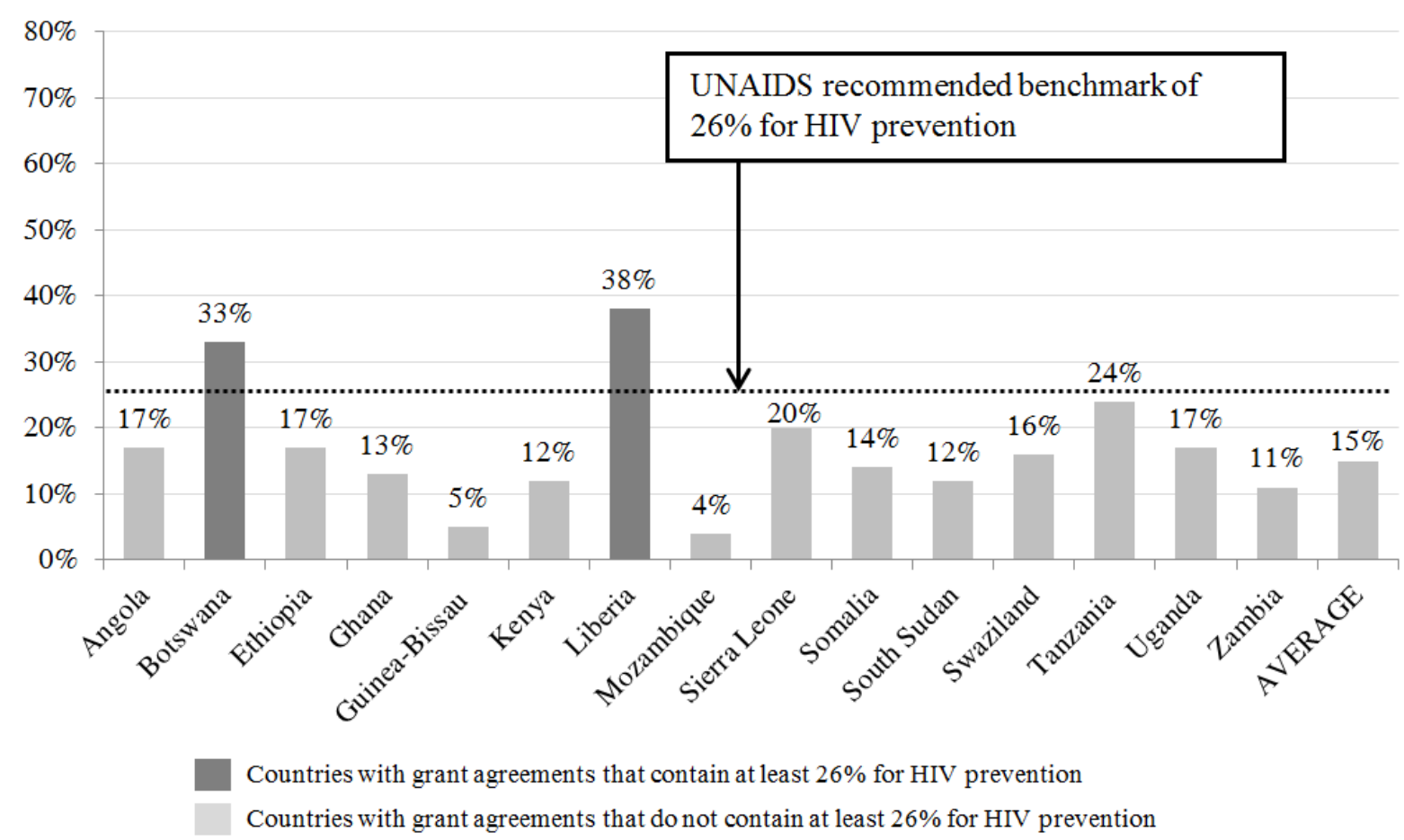

Figure 3. Proportion of HIV and TB/HIV Global Fund Signed Grant Agreements Dedicated to HIV Prevention Interventions (2014-2016 Funding Cycle)

Overall, across the 15 countries assessed, $69 \%$ of the prevention funding that was requested got included in signed grants. In actual figures, $\$ 381,267,152$ was requested for prevention, and $\$ 262,657,839$ was included in signed grants. Many countries requested significant portions of above allocation prevention funding, which is unlikely to be funded given limited Global Fund resources. Further, some of the requested funding might have been for interventions that the Technical Review Panel did not deem technically sound.

Among the sample, four countries - Angola, Sierra Leone, Somalia and Uganda - requested "a quarter for prevention" in their funding requests, yet their signed grants ended up being below the $26 \%$ threshold recommended by UNAIDS.

On the flipside, one country - Liberia - did not request "a quarter for prevention", yet its final grant includes prevention interventions worth more than $26 \%$ of the total. In fact, Liberia requested just $4 \%$ for HIV prevention, yet its signed grant contains $38 \%$ HIV prevention funding.

Proportionally, prevention funding for key populations (defined here as men who have sex with men, transgender people, sex workers and people who inject drugs) was slightly less likely to get included in signed grants than prevention funding overall.

In the 15 countries where both funding requests and signed grant agreements were available, $\$ 75,033,149$ was requested for key populations and $\$ 50,112,666$ was included in signed grants. This translates to $67 \%$ of key population prevention funding that was requested being included in signed grants.

The Global Fund aims to have investments in signed HIV and HIV/TB grants dedicated to programs targeting key populations reach $39 \%$ over the $2017-2019$ period. This analysis shows that less than $3 \%(\$ 50,846,315$ out of $\$ 1,747,483,074)$ is currently being invested in HIV prevention among men who have sex with men, transgender people, sex workers and people who inject drugs in 15 African countries.

Previous analyses have found similarly low levels of Global Fund investment in key populations. In countries with generalized epidemics, roughly $2 \%$ of total cumulative Global Fund investments from Rounds 1-10 in HIV prevention were allocated to sex workers [18]. A regional analysis covering Botswana, Malawi, Namibia, Swaziland, Zambia, and Zimbabwe, found that only $0.07 \%$ of Global Fund money went towards gay men, MSM and transgender individuals [19].

Importantly, the Global Fund's target speaks to treatment for key populations, as well as interventions to address social and structural barriers these groups face, but the difference between current prevention investments and the 2017-2019 investment targets of 39\% is striking nonetheless (Figure 4). 


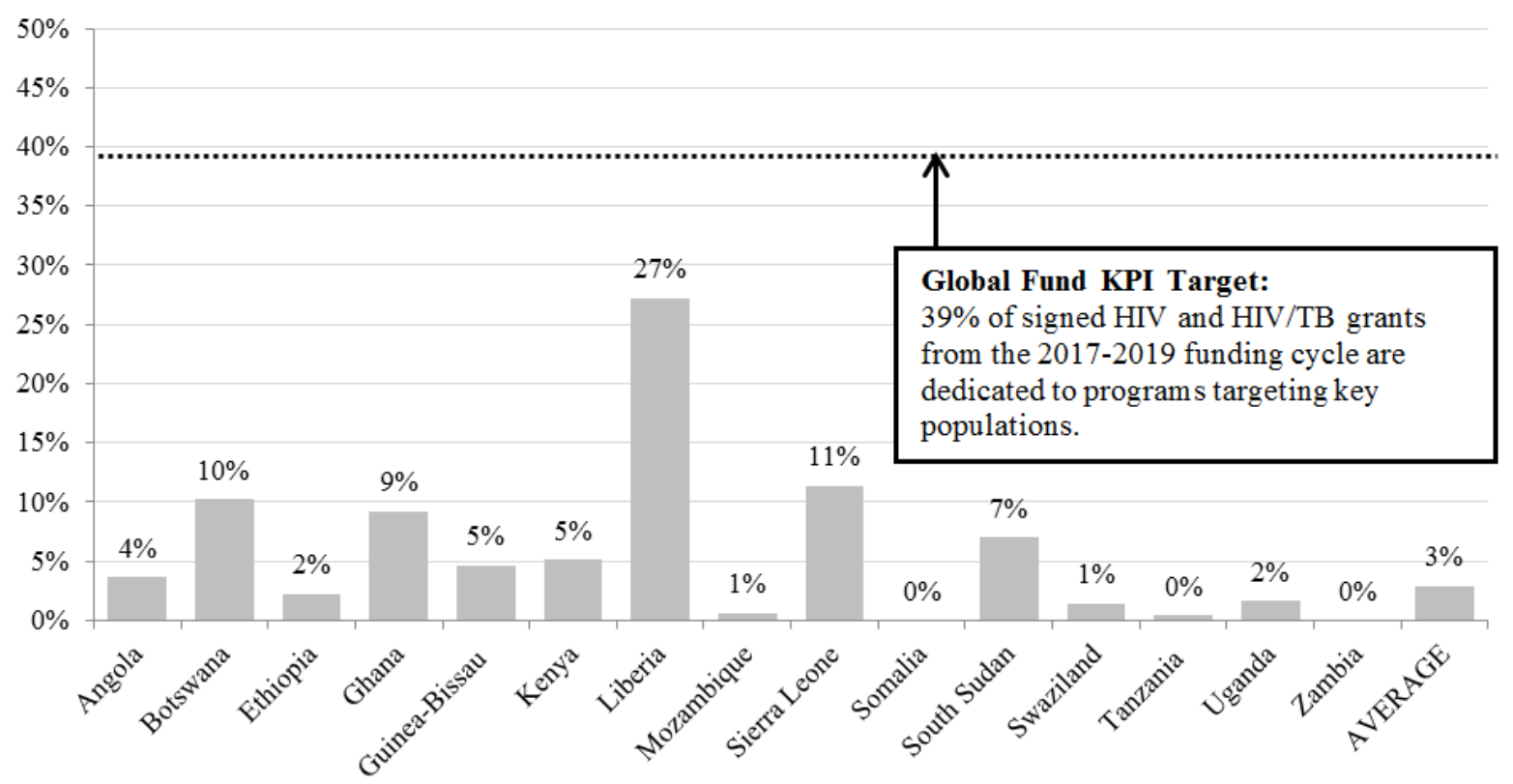

Figure 4. Proportion of Funding in HIV and HIV/TB Global Fund Signed Grant Agreements Dedicated to HIV Prevention among Men Who Have Sex with Men, Transgender People, Sex Workers and People Who Inject Drugs (2014-2016 Funding Cycle)

\section{Discussion}

Epidemiological and economic data from these countries helps to explain the amount of prevention funding that is requested and granted. There is a significant correlation between the number of new HIV infections which occur in a country per year, and the amount of HIV prevention funding that the country requested from the Global Fund in the 2014-2016 funding cycle. In other words, countries with more new infections requested more prevention funding. This is a very strong correlation $\left(r=.782^{* *}, p=.000\right)$.

However, this relationship is heavily skewed by South Africa, as an extreme outlier in terms of number of new infections (380,000/year).

Removing South Africa as an outlier, the relationship between new infections and prevention funding requested still remains significant $\left(r=.570^{*}, p=.013\right)$. In this sample, it appears that countries' funding requests for prevention are in line with their disease burden.

The correlation between the number of new infections and the amount of prevention funding included in signed grants is also significantly correlated, and even more strongly $\left(r=.582^{*}, p=.037\right)$.

There is also a strong correlation between the number of male circumcisions performed in a country and the total amount of HIV prevention funding it requested from the Global Fund in the 2014-2016 funding cycle. Among the 11 countries in this sample for which there is data on both indicators, countries that have performed a greater number of male circumcisions also requested more HIV prevention funding. This suggests that the number of male circumcisions performed could be an indication of how strongly a country prioritizes investments in HIV prevention.

However, the correlation between the number of male circumcisions and the amount of prevention funding included in signed grants is not significantly correlated $(r=.699, p=.081)$.

There is also a correlation between the wealth of a country, expressed as gross domestic product (GDP) per capita, and the proportion of funding requested for prevention $\left(r=.696^{* *}\right.$, $p=.000$ ) (Figure 5).

This is likely because wealthier countries are able to support more of their treatment liability with domestic funding, freeing up their Global Fund allocation to be spent on other priorities, including prevention.

For example, GDP per capita in Mozambique and Liberia is among the lowest in this sample $(\$ 1,192$ and $\$ 835$, respectively), as is the proportion of funding requested for prevention ( $3 \%$ and $4 \%$, respectively). In Liberia there is "severe dependence on donors for the HIV program" according to the country's funding request [20]. Similarly, in Mozambique, all HIV treatment is funded by external donors, with approximately $48 \%$ from the Global Fund and the remaining $52 \%$ from the U.S. Government [21].

By comparison, Mauritius and Botswana are the two richest countries in the sample, with a GDP per capita of $\$ 20,085$ and $\$ 15,839$, respectively. In Mauritius and Botswana, all ART is supported by domestic funding which enables these countries to dedicate large portions of their Global Fund funding requests to HIV prevention interventions (67\% and $44 \%$, respectively). 


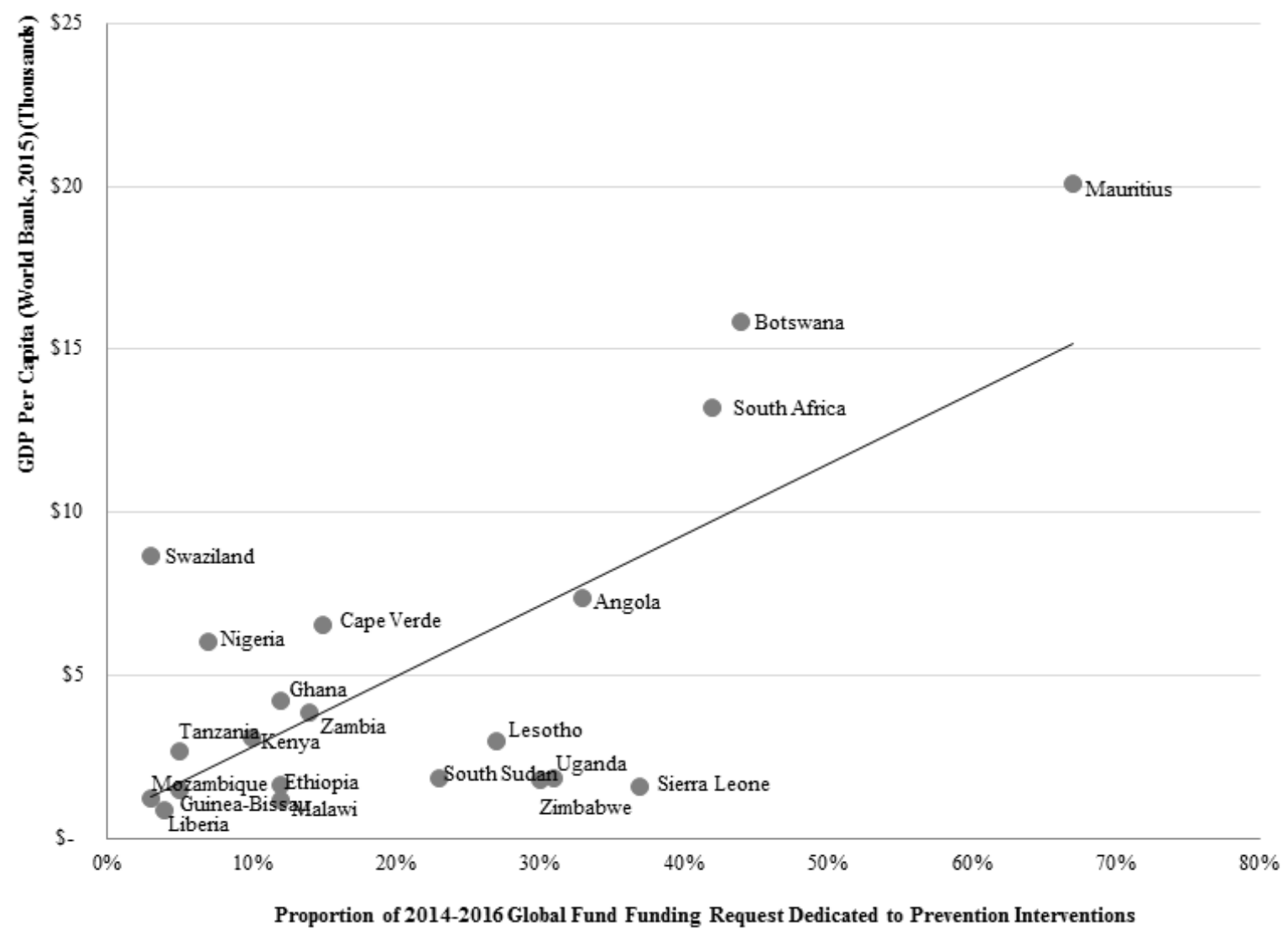

Figure 5. Correlation between GDP Per Capita and the Proportion of 2014-2016 Global Fund Funding Requests Dedicated to HIV Prevention Interventions $\left(r=.696^{* *}, \mathrm{p}=.000\right)$

Historically, Global Fund investments in HIV prevention were higher than they are now. Cumulative Global Fund grant expenditure on HIV prevention from 2002-2011 was $30 \%$ of all HIV spending [22]. This is higher than the funding requests and grant agreements examined in this sample (16\% and $15 \%$, respectively) and higher than the UNAIDS recommended level (26\%).

One reason why current prevention spending is lower (among this sample) than historical spending (2002-2011) is that millions more people now require sustained ART, much of is procured through Global Fund grants. This leaves less money for prevention.

Another important consideration is that many of the grants in this sample are integrated TB/HIV grants, and UNAIDS' $26 \%$ for HIV prevention recommendation uses a denominator of HIV funding only. To (crudely) control for this, one can adjust the total grant budget (the denominator) by the average disease split across Global Fund grants $(51 \%$ HIV, $18 \%$ TB and $31 \%$ malaria). This means that on average, TB/HIV grants are $74 \%$ HIV funding and $26 \%$ TB funding. With the adjusted denominator, the average HIV prevention funding in the signed grant agreements among the 15 countries examined becomes $20 \%$ - still below the $26 \%$ benchmark.

The 2016 Political Declaration includes recognition of the role that community organizations play in delivering prevention interventions, including a target to expand community-led service delivery to cover at least $30 \%$ of all service delivery by 2030 [10].

Community-led services are often funded and implemented by civil society organizations, community-based organizations, faith-based organizations, and other community structures. Conversely, facility-based services are usually funded and implemented by governments.

Among the 15 countries in this sample for which signed Global Fund grants for the 2014-2016 funding cycle are publicly available, a total of $\$ 185,195,041$ in HIV prevention funding is managed by a government principal recipient (PR). This represents $71 \%$ of all Global Fund HIV prevention funding in these 15 countries. By comparison, $\$ 61,948,901$ of HIV prevention funding in these countries is managed by civil society PRs, which is $24 \%$ of the total. In three countries - Angola, Somalia and South Sudan - UN Agencies are PRs, managing a total of $\$ 13,009,065$ in HIV prevention funding. This is $5 \%$ of total HIV prevention funding in the Global Fund grants of these 15 countries. Table 6 presents the amount of HIV prevention funding implemented by country and by type of PR. 
Table 6. HIV Prevention Funding in Signed Global Fund HIV and TB/HIV Grants in 15 African Countries, by Type of Principal Recipient (2014-2016 Funding Cycle)

\begin{tabular}{|c|c|c|c|}
\hline Country & $\begin{array}{c}\text { HIV Prevention Funding Managed by } \\
\text { Government PRs }\end{array}$ & $\begin{array}{c}\text { HIV Prevention Funding Managed by } \\
\text { Civil Society PRs }\end{array}$ & $\begin{array}{c}\text { HIV Prevention Funding Managed } \\
\text { by UN Agency PRs }\end{array}$ \\
\hline Angola & $\$ 0$ & $\$ 0$ & $\$ 5,013,116$ \\
\hline Botswana & $\$ 505,189$ & $\$ 8,374,333$ & $\$ 0$ \\
\hline Ethiopia & $\$ 47,141,780$ & $\$ 0$ & $\$ 0$ \\
\hline Ghana & $\$ 6,604,955$ & $\$ 3,920,701$ & $\$ 0$ \\
\hline Guinea-Bissau & $\$ 330,864$ & $\$ 11,709,992$ & $\$ 0$ \\
\hline Kenya & $\$ 24,095,539$ & $\$ 3,674,524$ & $\$ 0$ \\
\hline Liberia & $\$ 0$ & $\$ 7,550,109$ & $\$ 0$ \\
\hline Mozambique & $\$ 2,285,073$ & $\$ 6,329,952$ & $\$ 0$ \\
\hline Sierra Leone & $\$ 0$ & $\$ 0$ & $\$ 2,850,611$ \\
\hline Somalia & $\$ 0$ & $\$ 0$ & $\$ 5,145,338$ \\
\hline South Sudan & $\$ 0$ & $\$ 4,591,476$ & $\$ 0$ \\
\hline Swaziland & $\$ 2,733,513$ & $\$ 2,070,724$ & $\$ 0$ \\
\hline Tanzania & $\$ 66,889,991$ & $\$ 5,598,030$ & $\$ 0$ \\
\hline Uganda & $\$ 26,059,464$ & $\$ 8,129,060$ & $\$ 0$ \\
\hline Zambia & $8,548,673$ & $\$ 61,948,901$ & $\$ 13,009,065$ \\
\hline TOTAL & $\$ 185,195,041$ & & \\
\hline
\end{tabular}

In addition to being important implementers of HIV prevention services, civil society and communities also have vital roles to play in advocacy and accountability work. In one analysis, civil society's HIV priorities for Global Fund funding requests were analyzed based on civil society priorities charters that were produced in eight African countries: Kenya, Malawi, Swaziland, Tanzania, Uganda, Zambia, Zanzibar and Zimbabwe [23]. The charters are titled as "advocacy roadmaps" for civil society to lobby for the inclusion of their priorities in Global Fund funding requests.

In this analysis, behavior change interventions and programs for key populations were most commonly ranked as the top priorities for civil society in terms of what they wanted to see included in their Global Fund funding requests. Voluntary medical male circumcision was most commonly ranked near the bottom of civil society's priorities.

Civil society was found to be more successful at lobbying for the inclusion of priorities related to key populations, behavior change and condom promotion and less successful at lobbying for prevention for mother-to-child transmission, treatment and voluntary medical male circumcision.

While - on average - the majority of the countries in this sample are neither requesting nor being granted "a quarter for prevention" it is important to acknowledge that this is not a shortcoming unique to the Global Fund. Indeed, Global Fund investments are certainly not a complete picture of overall AIDS spending, nor are they the only development partner that could be spending more on HIV prevention.

At the very least, domestic funding and investments from the United States President's Emergency Plan for AIDS Relief (PEPFAR) need to be considered as part of the overall HIV prevention funding landscape. PEPFAR is the largest international funding partner in the AIDS response, making up approximately $66.4 \%$ of international HIV assistance in 2015 [24]. PEPFAR's planned spending on HIV prevention was $18.4 \%$ for 2016 [25].

Domestic funding is also an important aspect of the AIDS financing response. In 2014, 57\% of total investments for AIDS were domestic [26]. Cumulative investments from 2005-2013 in counties of all income brackets fall short of the $26 \%$ benchmark: $22 \%$ in low income countries; $23 \%$ in lower middle income countries; $18 \%$ in upper middle income countries [26].

\section{Conclusions}

In sum, of the countries sampled, an average of $16 \%$ of the total funding requested in HIV or TB/HIV funding requests to the Global Fund over the 2014-2016 funding cycle was dedicated to HIV prevention. Slightly less than this - $15 \%$ was included in the subsequent signed grant agreements. This is far below the UNAIDS' recommended benchmark of $26 \%$. The global goal of ending AIDS by 2030 will not be accomplished if HIV prevention continues to be under-prioritized.

Underspending on HIV prevention especially hurts communities that face disproportionate rates of new infections, especially adolescent girls and young women, men who have sex with men, transgender people, sex workers, people who use drugs, indigenous people, and people in detention.

Exploring ways to increase investments in HIV prevention is absolutely critical. 
Opportunities for increasing investments for HIV prevention in the East and Southern Africa region through Global Fund applications for the 2017-2019 funding cycle is one avenue.

Another opportunity lies in leveraging "Matching Funds", a new part of Global Fund grant architecture that incentivizes countries to direct more of their allocation amounts to certain strategic priorities, including key populations, human rights and adolescent girls and young women.

Advocacy from civil society and communities is absolutely vital, particularly on urging countries to request greater HIV prevention funding for key populations and adolescent girls and young women.

\section{Recommendations}

1. Encourage countries to increasingly absorb critical aspects of their HIV response - especially ART - into domestically-funded programs. This will enable the Global Fund to invest more in HIV prevention interventions, towards achieving the targets in its HIV prevention key performance indicators (Table 2) [7].

2. Perform community-led monitoring on HIV prevention budgets, for Global Fund, PEPFAR, government, and other funding streams. Having accurate, up-to-date and community-owned data on HIV prevention spending gaps is vital for effective advocacy.

3. Advocate for the health and rights of key populations, including sex workers, MSM, transgender people, people who inject drugs and prisoners. Criminalization and marginalization of these groups acts as a barrier to service delivery and access. This hampers the effective scale-up HIV prevention where it is needed the most.

4. Capitalize on opportunities with Catalytic Funding ("Matching Funds") as a new way to increase Global Fund investments in HIV prevention. Advocacy will be needed to ensure that countries dedicate the required amount in their allocation to the catalytic funding priorities, and that activities are prevention-focused wherever possible.

5. Support incentives to encourage countries to meet the $26 \%$ HIV prevention target, modelling successful initiatives such as the Asia Pacific Leaders Malaria Alliance, which has markedly, increased commitment to malaria programming in the Asia Pacific region [27].

\section{Acknowledgements}

The authors acknowledge support from the Centre for Social Science Research (CSSR) at the University of Cape Town and the Bill \& Melinda Gates Foundation. Portions of this research have been previously published as a discussion paper by the International Council of AIDS Service Organizations (ICASO). Sections have been reproduced here with permission.

\section{Abbreviations}

$\begin{array}{ll}\text { AIDS } & \text { Acquired immune deficiency syndrome } \\ \text { ART } & \text { Antiretroviral therapy } \\ \text { CSSR } & \text { Centre for Social Science Research } \\ \text { EANNASO } & \text { Eastern Africa National Networks of AIDS } \\ & \text { Service Organizations } \\ \text { GDP } & \text { Gross domestic product } \\ \text { HIV } & \text { Human immunodeficiency virus } \\ \text { ICASO } & \text { International Council of AIDS Service } \\ & \text { Organizations } \\ \text { KPI } & \text { Key performance indicator } \\ \text { MSM } & \text { Men who have sex with men } \\ \text { PEPFAR } & \text { The United States President's Emergency } \\ \text { PR } & \text { Plan for AIDS Relief } \\ \text { SPSS } & \text { Principal recipient } \\ \text { TB } & \text { Statistical Package for the Social Sciences } \\ \text { UNAIDS } & \text { Tuberculosis } \\ & \text { Joint United Nations Programme on } \\ \text { VMMC } & \text { HIV/AIDS } \\ & \text { Voluntary medical male circumcision }\end{array}$

\section{Symbols}

\begin{tabular}{|c|c|}
\hline $\mathrm{r}$ & $\begin{array}{l}\text { In statistics, the correlation coefficient " } r \text { " measures the } \\
\text { strength and direction of a linear relationship between two } \\
\text { variables on a scatterplot. The value of } r \text { is always between }+1 \\
\text { and }-1 \text {. }\end{array}$ \\
\hline $\mathrm{p}$ & $\begin{array}{l}\mathrm{p} \text { values indicate significance of a statistician relationship. A } \\
\text { small p-value (typically } \leq 0.05 \text { ) indicates strong evidence } \\
\text { against the null hypothesis, so you reject the null hypothesis. A } \\
\text { large p-value }(>0.05 \text { ) indicates weak evidence against the null } \\
\text { hypothesis, so you fail to reject the null hypothesis. }\end{array}$ \\
\hline * & Correlation is significant at the 0.1 level (2-tailed). \\
\hline$* *$ & Correlation is significant at the 0.05 level (2-tailed). \\
\hline$* * *$ & Correlation is significant at the 0.01 level (2-tailed). \\
\hline
\end{tabular}

\section{REFERENCES}

[1] UNAIDS. Prevention Gap Report, 2016. Online available from

http://www.unaids.org/sites/default/files/media_asset/2016-pr evention-gap-report_en.pdf.

[2] Human Sciences Research Council. South African National HIV Prevalence, Incidence and Behaviour Survey, 2012. Page xxiv, 2014.

[3] IBBS survey, 2013-2014, as cited on http://aidsinfo.unaids.org/

[4] Central Statistical Agency (Ethiopia) and ICF International. Ethiopia Demographic and Health Survey 2011. Calverton, Maryland, USA: Central Statistical Agency and ICF International, 2012.

[5] Ministry of Health and Child Care, National AIDS Council, UNAIDS, Centre for Disease Control and Prevention. Smart 
Investment to end HIV and AIDS in Zimbabwe based on a hotspot analysis, 2015. Online available at http://www.nac.org.zw/sites/default/files/Hot\%20spot\%20Ma pping\%20Report.pdf

[6] UNAIDS. Fast-Track: Ending the AIDS Epidemic by 2030. World AIDS Day Report. 2014. Online available at http://www.unaids.org/en/resources/documents/2014/JC2686 _WAD2014report

[7] UNAIDS. Invest in HIV Prevention. 2015. Online available at http://www.unaids.org/sites/default/files/media_asset/JC2791 _invest-in-HIV-prevention_en.pdf

[8] Kenya HIV Prevention Revolution road map: count down to 2030. Nairobi: Kenya Ministry of Health; 2014.

[9] South African National AIDS Council (SANAC) and National Department of Health. South African National Sex Worker HIV Plan 2016-2019. Online available at http://sanac.org.za/2016/03/29/south-african-national-sex-wor ker-hiv-plan-2016-2019/

[10] Political Declaration on HIV and AIDS: On the Fast Track to Accelerating the Fight against HIV and to Ending the AIDS Epidemic by 2030. Resolution adopted by the General Assembly on 8 June 2016 [without reference to a Main Committee (A/70/L.52)] 70/266. Online available at http://www.unaids.org/en/resources/documents/2016/2016-po litical-declaration-HIV-AIDS

[11] S. Resch, T. Ryckman \& R. Hecht. Funding AIDS programmes in the era of shared responsibility: an analysis of domestic spending in 12 low-income and middle-income countries. The Lancet Global Health, Vol.3, No.1, e52-e61. 2015.

[12] Global Fund. Results Report. 2016. Online available at https://www.theglobalfund.org/media/1122/corporate 2016re sultsreport_report_en.pdf

[13] M. Lloyed. Board approves new targets for the 2017-2022 Strategic KPI Framework. Global Fund Observer, Issue 308. Aidspan. 2017. Online available at http://aidspan.org/gfo_article/board-approves-new-targets-20 17-2022-strategic-kpi-framework

[14] Data retrieved from www.aidsinfo.unaids.org

[15] S. L. Davis, W. C. Goedel, J. Emerson \& B. S. Guven. Punitive laws, key population size estimates, and Global AIDS Response Progress Reports: an ecological study of 154 countries. Journal of the International AIDS Society, Vol. 20, No. 1.2017

[16] A. Green. Global Fund-supported programs suspended amid Tanzanian government crackdown on LGBT community. Global Fund Observer, Issue 307. Aidspan. 2017. Online available at http://www.aidspan.org/gfo article/global-fund-supported-pr ograms-suspended-amid-tanzanian-government-crackdown-1 gbt-0

[17] Personal communication with Karl Dehne, Chief Prevention Division at UNAIDS. Geneva, Switzerland. May $21^{\text {st }}, 2017$.

[18] O. Avdeeva, J .V. Lazarus, M. A. Aziz \& R. Atun. The Global Fund's resource allocation decisions for HIV programs: addressing those in need. Journal of the International AIDS Society, Vol.14, No.1, 51. 2011.

[19] O. Ryan, S. Baral, V. Bachman, A. Grosso \& K. Mason. Achieving an AIDS-Free Generation for Gay Men and Other MSM in Southern Africa. amfAR, The Foundation for AIDS Research and Johns Hopkins Bloomberg School of Public Health. 2013. Online available at http://www.amfar.org/uploadedFiles/_amfarorg/Articles/Arou nd The World/GMT/2013/MSM\%20Global\%20Report\%20 051613.pdf

[20] Liberia HIV Concept Note to the Global Fund. Online available at www.theglobalfund.org

[21] G. Oberth. Board approves costed grant extension to ensure continuity of HIV services in Mozambique. Global Fund Observer, Issue 293. Online available at http://www.aidspan.org/gfo_article/board-approves-costed-gr ant-extension-ensure-continuity-hiv-services-mozambique

[22] Global Fund. Strategic Investments for Impact: Global Fund Results Report, 2012. Online available at http://www.globalfundadvocatesnetwork.org/wp-content/uplo ads/2014/10/Publication_2012Results_Report_en.pdf

[23] G. Oberth, O. Mumba, L. Bhayani, \& Daku, M. Donor Agendas, Community Priorities and the Democracy of International HIV/AIDS Funding. Centre for Social Science Research (CSSR) Working Paper No. 372. University of Cape Town, 2016. ISBN: 978-1-77011-359-6. Online available at http://www.cssr.uct.ac.za/pub/wp/372

[24] The Henry J. Kaiser Foundation \& The Joint United Nations Programme on HIV/AIDS. Financing the Response to HIV in Low- and Middle-Income Countries: International Assistance from Donor Governments in 2015. 2016. Online available at http://www.unaids.org/sites/default/files/media_asset/financin g-the-response-to-HIV-in-low-and-middle-income-countries en.pdf

[25] Data online available at http://copsdata.amfar.org/s/2016

[26] The Joint United Nations Programme on HIV/AIDS. How AIDS Changed Everything. MDG6: 15 Year, 15 Lessons of Hope from the Response. 2015. Online available at http://www.unaids.org/sites/default/files/media_asset/MDG6 Report_en.pdf

[27] See www.aplma.org 